\title{
Art Deco cine: lo moderno necessário
}

\author{
Lourdes Luz (Brasil) \\ Universidade Veiga de Almeida \\ luz@uva.br
}

\author{
Nara Iwata (Brasil) \\ Universidade Veiga de Almeida \\ nara@uva.br
}

\begin{abstract}
Resumen
El trabajo presentado se centra en la lectura de los cines de Art Déco en todo el Río de las décadas de 1930 y 1940. El cine Art Déco fue diseñado como un espacio de neutralidad, la inevitable transición de eclecticismo del siglo XIX hasta la asepsia modernista. Con el fin de evocar el necesario moderno, se convirtió en una revisión crítica de la misma y Art Déco permite cambios formales y conceptuales, así como un análisis de los fundamentos teóricos que impregnaron el movimiento, tomado como paradigma de los Cines Metro.
\end{abstract}

Palabras clave: Art Déco, cines, Río, arquitectura

\begin{abstract}
This work focuses on the Art Deco, seen through film theaters of Rio de Janeiro between 1930 and 1940. The Art Deco applied to theater buildings, was created as a space of neutrality, key in the transition from nineteenth-century eclecticism to the aseptic modernism. To explore the modernist movement, this paper presents a critical review of the Art Deco and its background that provides a look at the conceptual and formal changes and an analysis of the theoretical basis of the movement, taking Metro theaters as a paradigm.
\end{abstract}

Keywords: Art Deco cinemas, River, architecture

$\begin{array}{lr}\text { FECHA DE RECEPCIÓN: } & 13 \text { de noviembre } 2012 \\ \text { FECHA DE REVISIÓN: } & 4 \text { de febrero de } 2013 \\ \text { APROBACIÓN: } & 19 \text { de febrero de } 2013\end{array}$

Para CItAR ESte artículo / to CITE thIS ARticle Iwata, N. y Luz, L. (2013). Art Deco cine: lo moderno necessário. Poliantea IX, (16), pp. 243-258. 
- Art deco cine: lo moderno necesario - Lourdes Luz \& Nara Iwata 


\section{Art Deco cine: \\ lo moderno necessário}

Lourdes Luz (Brasil)

Doctora en Bellas Artes

Nara Iwata (Brasil)

Maestra en Bellas Artes

\section{Art deco - gênese}

Para analisarmos o Art Deco inserido em um processo, importa escolher um ponto de partida para a análise, onde o que nos interessa são as questões pertinentes à industrialização. Portanto, traçando um histórico, não necessariamente cronológico, mas pinçando idéias e atitudes importantes para o trabalho, nomeamos a Revolução Industrial nosso marco.

A partir de então, novos elementos passam a fazer parte do processo sócio-econômico: a otimização da produção, a estandardização, a racionalização do trabalho, a diversificação do mercado e a integração da arte à vida. Não há mais a possibilidade da existência de um estilo que exprima a coerência da estrutura do sistema de arte de uma sociedade fechada. É necessária, então, uma nova estética.

Entretanto, apesar da velocidade impressa ao mundo ocidental, ainda é o passado que traz parte das respostas que deflagram as rupturas na arte, de modo geral. Buscar a originalidade é tarefa extremamente árdua, embora não imperativa, haja vista que muitas correntes continuaram a ancorar seus princípios nesse passado. Esse período é fragmentado e ambíguo, o que verificamos nas propostas individuais dos arquitetos, bem como naquilo que pertence aos condicionantes de um lugar. 
Na primeira metade do século XIX, o trabalho do profissional-arquiteto traz em seu bojo uma preocupação, ainda que embrionária, com o conforto do usuário e a funcionalidade do espaço produzido. $\mathrm{O}$ estilo, enquanto escolha e confecção de ornamentos, começa a não ocupar mais o primeiro lugar entre os problemas do arquiteto. Na segunda metade do século XIX evidencia-se otimismo e entusiasmo pela modernidade. Os problemas pertinentes ao conforto do ambiente, utilização das conquistas tecnológicas e a própria funcionalidade demonstram a demanda da classe burguesa, que explicita exigências quanto à eficácia de resultados.

Em fins do século XIX, essas questões vão sendo incitadas, principalmente no que diz respeito à validade do uso ou mesmo da existência do ornamento. De um lado possuímos defensores que nele vêem a própria expressão do prazer da vida, desde Viollet Le-Duc, figura central do revivalismo gótico na França a Louis Sullivan que utilizava o ornamento redesenhado em padrões geométricos ou baseado em um simbolismo mais orgânico. Em outro extremo encontramos, de modo pontual e solitário, o discurso de Adolf Loos, arquiteto vienense, que em 1908 escreveu "Ornamento e Crime" no qual criticava o uso abusivo da ornamentação na arquitetura européia do século XIX, posto que entendia que a ornamentação dizia respeito às sociedades artesanais e tem seu lugar assegurado na história, enquanto que para o século XX ela esconderia a potência ou lógica de produção desse mundo, que é o racionalismo. Para Loos, o ornamento retardaria o avanço, seria um anacronismo e implicaria na perda de trabalho, capital, material e tempo. Só à nobreza interessaria o ornamento, porque evitando o seu desaparecimento ao mesmo tempo evitaria a libertação do operariado. Sua postura vem em defesa da razão, do gosto, bem como da moral.

A busca do novo também se faz através do Art Nouveau, mas subjacente a ele, temos o conceito de moda, com o sentido e importância que assume nessa sociedade industrial. E moda vem a ser um fator psicológico, onde há o interesse por um tipo de produto mais recente e um desprezo pelo velho. Quando citamos a sociedade industrial, o fazemos nos referindo à burguesia moderna que está tomada de entusiasmo pelo progresso, dado que a 
caracteriza. $\mathrm{O}$ ambiente criado pelo Art Nouveau oferece a este grupo uma imagem de si mesma idealizada e otimista, que de certa forma ameniza a dramática condição de servilismo com respeito ao capital.

O Art Nouveau e o Art Deco, apesar de formalmente distintos, expressam a força de uma sociedade de massa, na qual os objetos e as soluções são servidos às pessoas de maneira a serem engolidos sem deglutição, o que é próprio de uma cultura de massa que impõe um gosto e valores formais. Não obstante, esses movimentos abrem os olhos da maioria, pela primeira vez, para esferas da vida com que nunca contataram.

Apesar da existência de uma cultura de massa na primeira metade do século XX, o design é trabalhado a partir de formas criativas e preenchendo, em certa medida, as necessidades reais dos homens. Posteriormente, o utilitarismo ocupa o espaço e a forma tende a ser mais atraente. É fundamental para o prosseguimento da análise que conceitos pertinentes a essas questões sejam levantados: ressalvamos que a era industrial, bem como uma indústria cultural e cultura de massa, só vão existir a partir da Revolução
Industrial. Embora não seja uma condição sine qua non, é necessária uma economia de mercado, uma economia baseada no consumo de bens, isto é, a evidência de uma sociedade de consumo. (Coelho, 1980, p.32-33)

A indústria cultural foi impulsionada e conheceu o desenvolvimento a partir do espírito capitalista, o que não significa que não possa existir sob qualquer tipo de regime político-econômico. De todo modo, intimamente ligada a uma indústria cultural, há uma organização burocrática que filtra e seleciona a idéia criativa, o que, por conseguinte, pesa, estabelecendo perfis na produção de uma cultura de massa.

Essa produção se destina ao máximo consumo, deve, portanto, ser dinâmica e se dirigir a um público universal o que tende a um ecletismo, enquanto adjetivo. A cultura de massa é animada pelo duplo movimento: o imaginário arremedando o real e o real que toma as cores do imaginário, sendo esta uma de suas características fundamentais. A produção gera não só um objeto para o sujeito, mas também um sujeito para o objeto, o que nos leva a compreender a concepção de um público de massa e universal. 
O Art Nouveau entendido como estilo de massa, com suas complexas linhas curvas, internacionalizou-se na década de 1890 e teve seu apogeu em 1900. Desenvolveu-se em vários setores: pintura, escultura, artes gráficas e decorativas, até o ponto em que começou a se deteriorar, por vezes se vulgarizando.

Os primeiros sinais neste sentido se encontram na obra do arquiteto Charles R. Mackintosh, que despoja o Art Nouveau de ornamentos gratuitos, com uma depuração ou abstração crescente de motivos naturalistas: eliminação das curvas e cores em favor do preto e do quadrado branco, redução do volume em favor do plano e o abandono de referências do mundo real. A geometria para Mackintosh é um dos instrumentos para a liberação da forma enquanto tal e já nos primeiros anos do nosso século assume um maior significado, como sendo o único meio de se alcançar fundamentos sólidos em direção ao novo.
Mas suas propostas são, a princípio, circunscritas à cidade de Glasgow. (fig. 1a)

Podemos dizer que essa combinação quase racional dos modelos ornamentais se destaca também no final do século XIX, nas propostas do grupo da Secessão Vienense, onde estão presentes sentimentos de revolta, na medida em que rompe com as instituições oficiais de arte e evidencia uma preferência pela simplicidade das linhas geométricas. Para o grupo guiado por Otto Wagner, a arquitetura deveria libertar-se de toda a imitação e levar em conta as condições técnicas modernas. Eram emergenciais modificações dos valores formais: sair do relevovolume e chegar ao plano. A renovação da cultura artística na última década do século XIX não é súbita, os discursos são feitos referendando o passado que serve, continuamente, como termo de comparação para um ideal que se queria alcançar. (fig.1b) 


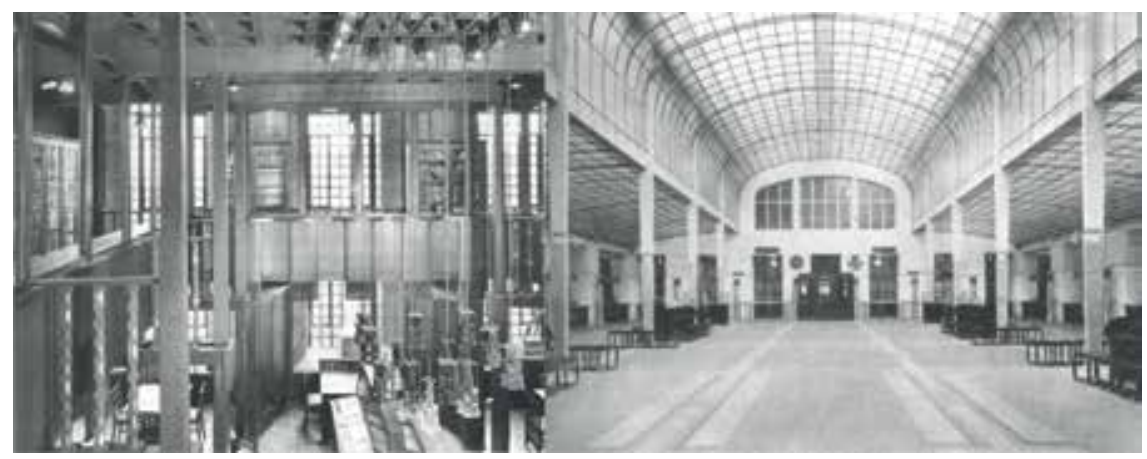

Figura 1a - Mackintosh, Escola de Arte de Glasgow, Biblioteca, 1905-1909. FRAMPTON, Kenneth. História crítica da arquitetura moderna. São Paulo: Martins Fontes, 1997. p.83. Figura 1b - Otto Wagner, Caixa Econômica da Agência dos Correios, Viena, 1904. FRAMPTON, Kenneth. História crítica da arquitetura moderna. São Paulo: Martins Fontes, 1997. p.93.

O Art Deco, no que diz respeito a um modelo formal, possui um sistema fechado e código próprio. Todavia, sua aspiração em tornarse universal e obter livre trânsito às propostas a ele contemporâneas, de modo a assimilar o que quisesse e fosse interessante, expressando o espírito da época, permite-nos inseri-lo na modernidade, enquanto proposta. $\mathrm{O}$ uso de várias linguagens é um ato de liberdade de escolha, o Art Deco é uma fusão simbólica do futuro com o passado, no presente, e mais ainda a fusão do real com a fantasia e o lúdico. (Gonçalves, 1990, p.56)

\section{0 cinema: "luxuoso, moderno e confortável"}

Elegemos o Cinema como objeto de análise no universo Art Deco, na medida em que no rastreamento da modernidade, estes edifícios se tornam símbolos de uma época, mais do que qualquer outro programa de arquitetura e onde se encontram os mais extravagantes exemplos Deco. O cinema serve de referência de urbanidade, contribuindo na constituição de uma nova relação entre o público e o cotidiano, interferindo nos seus hábitos culturais e sociais. Vemos, portanto, o Cinema como agente educador do público de um modo geral, o lugar onde se apresenta a vida moderna, ou aquilo que se pensava ser moderno. O Cinema integra o homem à própria vida.

O Cinema consegue revelar "a beleza secreta, a beleza ideal dos movimentos e ritos do cotidiano", e, é elogiado "em função de sua filiação 
técnica e industrial bem como pela sintonia com as novas condições da experiência sensorial, testemunhada pelo dinamismo de sua imagem". (Campos, 1991, p.40) A ciência é o mito moderno, o fetiche, e o Cinema é uma das modalidades de torná-la táctil.

Hollywood, a cidade do sucesso efêmero, a cidade de miragens, com a primazia nesta atividade, protagonizará a divulgação da concepção de uma modelo que chegará ao Brasil na década de 1920: tentando impor uma modernização através da exibição, propriamente dita, bem como de uma arquitetura emergente, "apelidadas de elefantes brancos, construídos com o luxo necessário para fazer pendant com os mistérios e fortunas dos filmes que projetavam". (Arestizabal, 1984)

Esse modelo que mencionados, está menos ligado ao decorativismo francês Art Nouveau das primeiras salas de cinema e mais empenhado em repetir Hollywood no Brasil, não só Hollywood, mas Estados Unidos de um modo geral. Já em 1910, faziam-se altíssimos investimentos na construção de verdadeiros palácios cinematográficos, para atendimento de uma clientela obcecada pela arte da nova civilização, assim como ávida pelo consumo de um novo produto.

Esses novos cinemas, como o Íris, possuíam um estilo entre o ecletismo e o Art Nouveau, cuja matriz era, provavelmente, a Ópera de Paris, com todo o aparato do teatro e a significativa presença dos balcões. Um espaço concebido para ser teatro não deveria funcionar como cinema e vice-versa, uma vez que no teatro, por exemplo, os balcões têm uma função simbólica: não necessariamente, deste local se terá a melhor visão do palco, diríamos que importa menos ver que ser visto. Já o cinema requeria outras exigências, entre as quais visibilidade da tela propriamente dita é o fator primordial.

Segundo a crônica da época, o consumidor-espectador nesse caso é mais requintado que aqueles dos antigos cinemas, o que poderia, mesmo que virtualmente, conjugar com aqueles interesses do teatro. $\mathrm{Na}$ década de 1920, indubitavelmente, ir ao cinema tinha um caráter lúdico. O espectador era recebido, de modo geral, por funcionários treinados, inclusive com noções de etiqueta, a fim de fazer a transposição do real à fantasia. Em sessões especiais, porteiros e bilheteiros passavam o 
espírito do filme através da própria indumentária. Em certo sentido, perpetua-se uma teatralidade barroca. Aqui, subjaz o modelo francês do fin-de-siécle no que tange ao ornamento e à própria produção do espaço. Ainda que a função simbólica se sobreponha à utilitária, a sociedade traduz novos padrões.

\section{Arquitetura dos cinemas cariocas: forma \& funç̃õo}

Quando o assunto é cinema, é impossivel não mencionar o nome de Francisco Serrador, empresário ousado que propôs fazer da Cinelândia uma pequena Broadway, com cinemas, teatros, hotel, lojas, parque de diversões, salas de escritórios, restaurantes. Esse visionário pretendia concretizar uma cidade de divertimento e lazer, com nível compatível com o que considerava moderno, em termos de estrutura. $\mathrm{O}$ projeto não foi colocado em prática em sua totalidade, porém importa menos sua ação que sua intenção. Nossa mini-Broadway deu partida para a implantação do novo empreendimento.

$\mathrm{Na}$ década de 1930, alguns bairros da Cidade do Rio de Janeiro passaram a abrigar esse novo serviço cultural e podemos destacar a Tijuca, e em especial a Praça Saens Peña, que recebeu o codinome "Cinelândia da Tijuca", tal a concentração de salas luxuosas nessa área. E Copacabana, onde o primeiro cinema foi fundado em 1910. Em 1931, com o propósito de fornecer algo a mais a seus clientes, o Cinema Atlântico (inaugurado em 1920) na avenida Nossa Senhora de Copacabana próximo à rua Siqueira Campos, por exemplo, promovia as Sessões da Elegância, quando o público alvo, senhoras e senhoritas, estabelecia o critério para a seleção dos filmes e era motivo para que o ambiente recebesse agradável fragância. (Cardoso, 1988, p.97)

A Sala de Cinema foi concebida por arquitetos que não tinham se dado conta senão do aspecto inerente ao "espetáculo", deixando para segundo plano aspectos importantes como visibilidade daquilo que seria exibido na tela. $\mathrm{O}$ teatro por tradição devia ser espaçoso para fazer face à afluência e ser muito ornamentado para convir à elegância e propiciar admirações mútuas durante os entre-atos.

As possibilidades do cinema vão sendo introjetadas aos poucos no público e no profissional de arquitetura e engenharia. Há uma 
perda da aura da obra de arte, na medida em que se viabiliza a repetição do espetáculo de forma reiterada e contínua, sem entre-atos. $\mathrm{O}$ cinema comporta-se frente ao público como as lojas comerciais com suas múltiplas sucursais: distribui o prazer, visto aí, como mercadoria, nas horas e dias de lazer comum, diferentemente do teatro com representações exclusivas, uma vez que cada dia de apresentação de uma peça traz no seu bojo a unicidade.

Os arquitetos, a partir dessa conscientização, exercem uma outra postura que visava solucionar problemas relativos a segurança, circulação, visibilidade, conforto e acústica. Deste modo, o edifício passou a privilegiar a função utilitária, na qual a fachada serviria somente de moldura para a publicidade.

A terceira geração de cinemas, nosso objeto de estudo, nasce dessas expectativas. E no Rio de Janeiro, temos como divisor de águas e cerne da questão, as inaugurações dos Metro Passeio, Tijuca e Copacabana, que trouxeram dos Estados Unidos um modelo e estabeleceram uma tipologia.

Citamos os três cinemas da cadeia Metro, entretanto é o do Passeio (inaugurado em 26 de setembro de 1936) o ponto nevrálgico, onde estava inerente a ideologia do poder da indústria cinematográfica, apesar da existência de cinemas anteriores que adotaram o modelo americano, como verificaremos adiante.

O Metro Passeio (Revista Arquitetura e Urbanismo, 1936, p.196202) era de propriedade da firma Loew's Inc. de Nova Iorque, empresa que na época era detentora de mais de 350 cinemas espalhados pelo mundo. Hoje em seu lugar, encontra-se o Cinema Metro Boavista, sem praticamente, nenhuma referência ao original. O programa de um edifício para cinema no pavimento térreo e escritórios nos outros pisos foi desenvolvido pelo arquiteto Robert Prentice com a colaboração de Adalbert Szilard.

A grande sala de espera, luxuosamente decorada no estilo D.João $\mathrm{V}$ representando resquícios da tradição aristocrática, estava ligada às lojas e sanitários, o que caracterizava o condicionante conforto para os usuários. Uma platéia de grandes dimensões, o que neste caso somavase ainda um balcão, cuja escada de acesso inseria-se no espaço do auditório e apresentava também outros compartimentos de apoio. Destacavam-se as seis saídas laterais o que 
garantia um escape rápido e eficiente em situações de emergência. (fig.2a)

A novidade assinalada (Revista Arquitetura e Urbanismo, 1936, p.196-202) era o tratamento acústico e o condicionamento de ar (sistema "Carrier", instalado pela General Eletric). Quanto à fachada principal era curvilínea, em conseqüência da planta da sala e para solucionar a esquina das duas ruas. $\mathrm{O}$ arquiteto idealizou nesse encontro, uma torre na qual locou escritório em cada andar, um elevador e na parte superior a caixa d'água. $\mathrm{O}$ tratamento externo da fachada era marcado por linhas verticais e trazia o gosto Deco, que no interior se mesclou com as formas mais requintadas do estilo D.João $\mathrm{V}$, porém a geometria dominava o conjunto. (fig.2b)

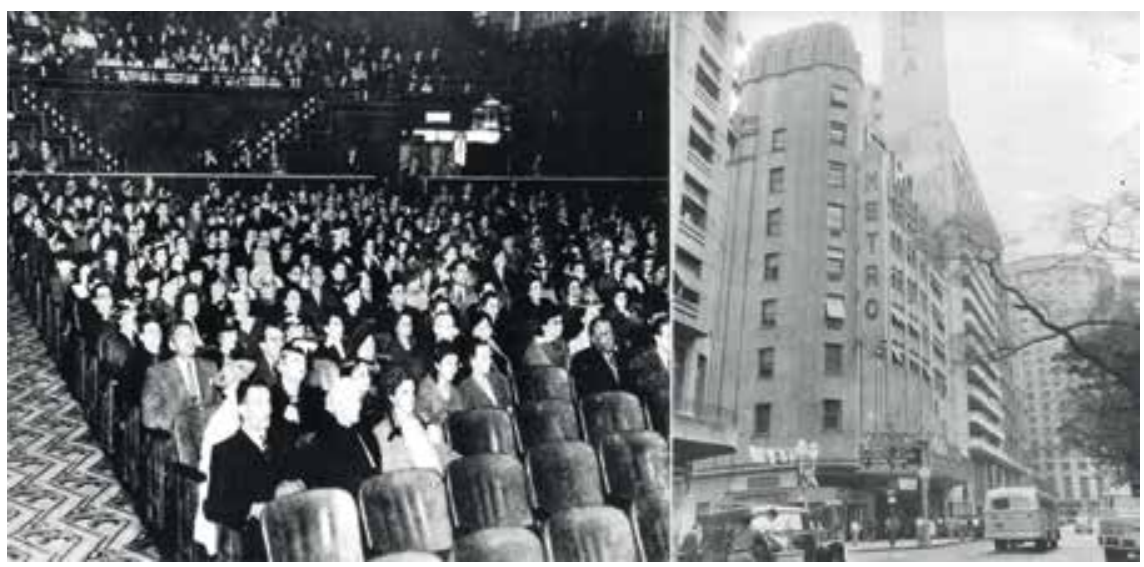

Figura 2 - Cinema Metro Passeio. Arquivo Geral da Cidade do Rio de Janeiro

O Metro Tijuca, na Praça Saens Peña (demolido), foi inaugurado em 10 de outubro de 1941, com projeto de autoria de Adalbert Szilard, que havia participado da equipe de Prentice no Metro Passeio.

Artigo no Jornal do Brasil da época fez bela descrição do edifício, em que pese alguma parcialidade: "Pode se asseverar, sem exagero, que casa de espetáculo, desse gênero, não se pode desejar melhor. Tudo quanto diz respeito à eficiência e ao conforto foi pensado com carinho e melhor realizado. $\mathrm{O}$ aspecto da sala é imponente. Sua decoração é sóbria, casa-se bem às poltronas de um verde claro igual aos ornamentos do tapete que acolchoa todas as passagens e escadarias, de um 
bonito desenho, de modo a emprestar ao ambiente um tom de suprema elegância. São confortáveis as poltronas, as filas bem espaçadas e dispostas na sala em acentuado declive, de modo que não há um só lugar que possa ser considerado mau. São cerca de 2000 lugares, somando-se os do balcão. A iluminação é profusa e bem disposta. A refrigeração atende a todas as exigências do nosso clima e é perfeita como constituem a última palavra os aparelhos de projeção e som. São amplas as salas de espera, excelentes e profusos gabinetes sanitários. Está a Tijuca dotada de um cinema tão bom, senão melhor que o Metro da rua do Passeio ..." (Jornal do Brasil, 1941)
A planta baixa obedeceu à concepção espacial do Metro Passeio, sendo que a diferença estava na escadaria que levava ao balcão, implantada, neste caso, no hall de entrada. Devido às imposições do próprio terreno, não havia saídas laterais, entretanto, identificavam-se grandes vãos em todos os acessos, tanto principais como secundários. E como mencionou o artigo do jornal, e ratificado pelas informações provenientes da Revista Arquitetura e Urbanismo (Revista de Arquitetura e Urbanismo, 1942, p.13-22), todo o projeto defendeu a concepção Art Deco, das linhas verticais nas fachadas ao desenho nos pisos e tetos. (fig.3)

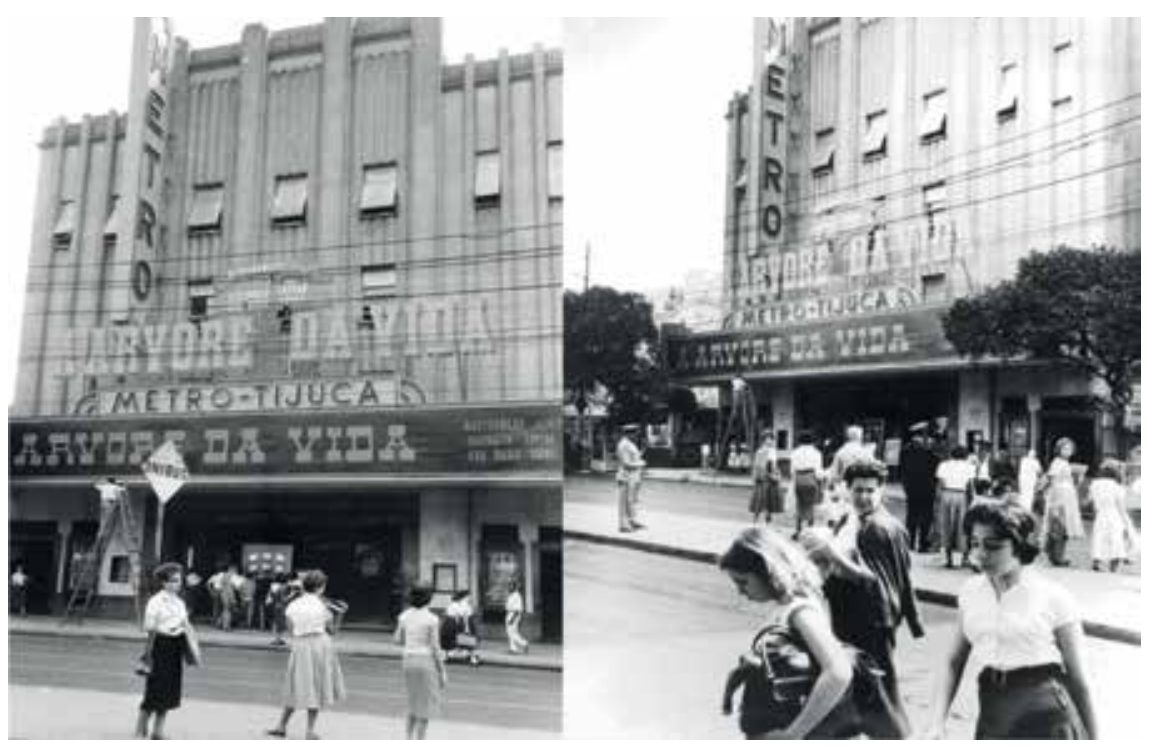

Figura 3 - Cinema Metro Tijuca. Arquivo Geral da Cidade do Rio de Janeiro 
Com a inauguração do Metro Copacabana (avenida Nossa Senhora de Copacabana) em 05 de novembro de 1941, com projeto de autoria de Robert Prentice, firmou-se o processo de descentralização dos cinemas, cuja concentração se dava, até então, na Cinelândia. Talvez, por ser o último da série Metro no Rio de Janeiro, ou pelo fato da sua inauguração ter sido tão próxima do Metro Tijuca, foi o menos noticiado na imprensa e em revistas especializadas. Além do que os valores formais se repetiram o que poderia ter ocorrido também nos interiores, mas não podemos nos assegurar da assertiva (o cinema foi demolido na década de 1970).

Todavia dois artigos do Diário Carioca nos mostram, direta ou indiretamente, sua importância para o bairro de Copacabana: "cinema de padrão impar entre nós, de modelo que até aqui só existia nos Estados Unidos, o Metro Copacabana empolgará por seu conforto, seu luxo, sua elegância, sendo as 2000 poltronas luxuosamente estofadas e todas suas dependências beneficiadas por perfeito aparelhamento de ar condicionado". (Diário Carioca, 1941) "A multidão que ontem abarrotou o luxuoso, amplo, sensacional Metro
Copacabana não vistoriou apenas uma belíssima casa de espetáculos que honra a cidade e que lançou entre nós um padrão que até aqui só existia nos Estados Unidos" (Diário Carioca, 1941) (fig.4)

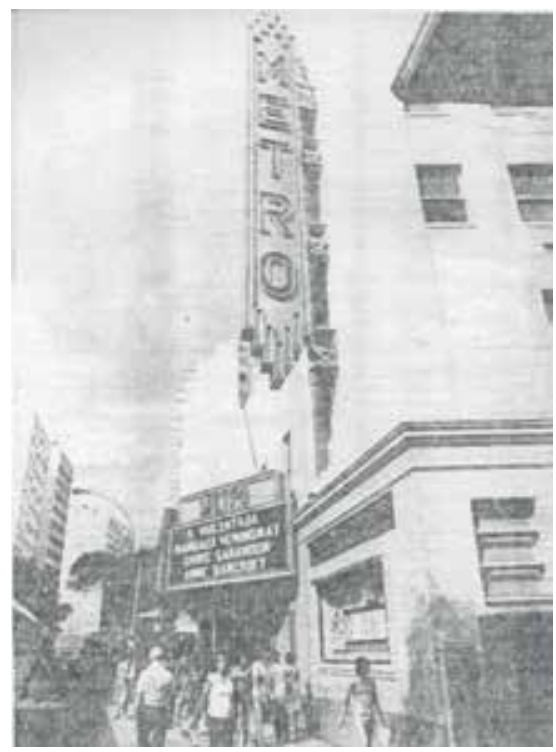

\section{Considerações finais}

O Rio de Janeiro, desde antes da Primeira Guerra Mundial e mais acirradamente depois desta, enfrenta uma tensão, posto que se propõe a passar da condição provinciana a cosmopolita, e não há, naquele momento, possibilidades de conviver com obstáculos: serão eles transpostos ou camuflados. Não há como negar que o cinema, tanto no que diz respeito à película quanto 
à arquitetura-invólucro está assente na questão da cultura de massa, onde é excludente um projeto que ligue a experiência do passado e a expectativa do futuro. Quando o foco é cultura de massa importa o presente para o autor, e para aquele que consome.

Nosso propósito é aproximar o abstrato-conceito do concreto-cinemas, e aí, apesar do caráter perecível e fugaz do Art Deco, os cinemas projetados e construídos sob sua égide arriscaram para viabilizar uma possibilidade de novo, num projeto onde o novo pode converter-se em moderno, dado seu conjunto de qualidades, em um esforço de absorver o possível.

O cinema é a alegoria daquela contemporaneidade, é símbolo de uma época. O homem sonha, fantasia, imagina e vive mais em função do que ele pode ser, nem que seja na pura aparência do que ele é, e quanto mais entediante seu cotidiano, mais exigente é em relação à mercadoria, daí sucesso do Art Deco na Europa depois da primeira Guerra Mundial e na América pós-Depressão. Essa situação tem rebatimento no Brasil em geral e especificamente na cidade do Rio de Janeiro.

\section{Referências bibliográficas}

Albretch, Donald. (1986). Desining Dreams - Modern Architecture in the Movies. New York: Harper in collaboration with the Museum of Modern Art.

Araujo, Vicente de Paula. (1976). A Bela Época do Cinema Brasileiro. São Paulo: Ed Perspectiva.

Arestizabal, Irma. (1984). 100 Anos. Rio de Janeiro, Funarte, Instituto Nacional de Artes Plásticas, PUC / Solar Grandjean de Montigny.

Arestizabal, Irma; Grimberg, Piedade \& Virzi, Antonio. (1989). In, Arquitetura Revista. Rio de Janeiro, FAU/UFRJ, v.7, p.35-42.

Bouillon, Jean Paul. (1989). Art Deco 1903-1940. New York: Skira-Rizzoli.

Campos, Fernando Ferreira. (1991). Na Sala de Espera do Cinema Odeon. Rio de Janeiro: Sec Municipal de Cultura, Turismo e Trransportes, Depto Geral de Documentação e Informação Cultural, Arquivo Geral da Cidade do Rio de Janeiro.

Cardoso, Elizabeth Dezouzart; Vaz, Lilian Fessler; Albernaz, Maria Paula; Aizen, Mario \& Pechman, 
Robert Moses. (1991). História dos Bairros, Memória Urbana - Copacabana. Rio de Janeiro: João Fortes / Index.

Coelho, José Teixeira. (1991). O que é Industria Cultural ? São Paulo: Brasiliense.

Conde, L Paulo; Nogueira, Mauro Neves; Almada, Mauro \& Souza, Eleonora F. (1986). "Protomodernismo em Copacabana”. Arquitetura Revista, n.3, p.40-49.

Duncan, Alastar. (1985). Mobilier Art Deco. Fribourg: Office du Livre.

Figueiredo, Luciano; Ramos, Oscar. (1980).Rio Deco. Rio de Janeiro, Achiamé, João Fortes.

Frampton, Kenneth. (1987). História crítica de la Arquitectura Moderna. Barcelona, Gustavo Gilli.

Gonçalves, D. (1971). Resenha do livro L'Architettura dell'Ecletismo de Luciano Patetta. Rio de Janeiro: Programa de Pós Graduação em Artes Visuais EBA/UFRJ, 1990.

Hiller, Bevis. (1971). The world of Art Deco. Nova Iorque: E P Dutton.

Klein, Dan; Mc Clelland, Nancy A.; Haslam, Malcolm. (1987). In the Deco Style. London: Thames \& Hudson.

Lesientre, Alain. (1962).The spirit and splendour of Art Deco. New Jersey, Castle Books.

Morin, Edgar. (1962). L'Espirit du Temp. Paris, Grasset.

Pevsner, Nikolaus. (1980). Os pioneiros do desenho moderno. São Paulo: Martins Fontes.

Vieira, João Luiz \& Pereira, Margareth Campos. (1983). Espaço do Sonho: Cinema e Arquitetura no Rio de Janeiro, pesquisa apresentada à EMBRAFILME no projeto Cinemateca.

Weber, Eva. (1985). Art Deco in América. New York: Exeter Books.

Weimer, Gunter. (1991). "O "Estilo" Art Deco". Revista Projeto, 151 pp.26-44.

Wirz, H; Striner, R. (1984). Washington Art Deco. Washington: Smithsonian Instituin Press, 1984.

\section{Material de leifura adicional}

Arquitetura e Urbanismo, novembro e dezembro de 1936. 
Arquitetura e Urbanismo, janeiro e Arquivo Geral da Cidade do Rio de fevereiro de 1942.

Diário Carioca, 4 de novembro de 1941 Janeiro, documento 1780, pasta 39, ano 1914.

Diário Carioca, 6 de novembro de 1941 Arquivo Geral da Cidade do Rio de Janeiro, documento 237

Arquivo Geral da Cidade do Rio de

Jornal do Brasil, 10 de outubro de 1941 Janeiro, documento 21369, caixa 11, ano 1919. 